\title{
Pablo y Jesús. \\ La vida de Jesús y la vida de Pablo.
}

\section{Josep Oriol Tuñí,. Facultad de Teología de Cataluña.}

El tema Pablo-Jesús es tan conocido y ha sido abordado tantas veces en la época crítica que resulta difícil analizarlo una vez más sin recaer en tralamientos ya conocidos o en reflexiones repetidas una y otra vez. Porque, aunque no haya sido objeto de estudios o evaluaciones en nuestro ámbito cultural, ${ }^{1}$ sin embargo, continúa siendo uno de los temas más apasionantes de la época crítica que es necesario situar y justificar en cualquier caso.

Revisar la historia del tema desde sus origenes resultaria una tarea excesivamente ardua que, además, ouros han hecho con cierto detalle. ${ }^{2}$ Sin embargo, de la misma pueden deducirse algunas consecuencias que son relevantes para nuestro tema. Como resumen podrlamos decir que se perciben tres grandes elapas en la investigación de la relación Pablo-Jesús.

La que va de F. Chr. Baur (1831) a W. Wrede (1905, cfr. también A. Schweitzer ${ }^{3}$ ), la cual se caracteriza por el esfuerzo en subrayar la importancia de la teología paulina en los orígenes del cristianismo. En el fondo se trata de ver si Pablo es el verdadero y definitivo catalizador de los orígenes cristianos. Para decirlo de forma más aguda: se trata de evaluar si Pablo ha sido el verdadero fundador del cristianismo. 4

La segunda elapa está marcada por la aportación de R. Bultmann. En esta etapa se da un enfoque muy conocido y hasta cierto punto familiar a la relación Pablo-Jesús: en contraste con la tradición sinóptica, la tradición paulina no muestra interés alguno por la vida de Jesús. Ni los fragmentos narrativos de la tradición evangélica ni, en otra línea, la tradición de logia de Jesús encuentran eco en la tradición paulina. ${ }^{5}$ Se puede decir que esta etapa llega hasta nuestros dias y que todavía hoy se encuentran opiniones que mantienen esta línea ${ }^{6}$ Aunque, justo es decirlo, los afios transcurridos han impuesto una serie de matices tanto al mismo Bultmann como a sus seguidores. ${ }^{7}$ 
Una tercera y última elapa surge de una cicrta reacción e incluso oposición a la tesis bultmanniana. Los estudios sobre el tema publicados en los últimos años muestran una doble tendencia: completar la posición de Bultumann ${ }^{8}$ o más bien un rechazo de la tesis bultmannianana ${ }^{9}$ Sin embargo, es necesario dejar constancia de que no hemos llegado a posturas claras y definidas que puedan ser calificadas como soluciones de esta complicada relación.

Podríamos decir, con el peligro evidente de simplificar, que la problemática se ha centrado poco a poco en un punto capital que no ha alcanzado suficiente madurez: Pablo no parece mostrar un interés específico por aquel que ha sido llamado por la investigación neotestamentaria "el Jesús histórico." La leología de Pablo no ha llegado a integrar salisfactoriamente la "historia de Jesús." 10 Por ello conlinúa siendo una cuestión abierta la pregunta por la continuidad entre Jesús y Pablo. O, lo que es lo mismo, la pregunta sobre hasta qué punto Pablo ha cambiado o transformado fundamentalmente los planteamientos y la intención de Jesús. 11

De hecho aquí tenemos un problema de la actual rellexión teológica y, más en concreto, de la cristología. Esto se puede mostrar de múltiples maneras. Vamos a mencionar dos. En primer lugar, la rellexión cristológica actual que toma tan en serio la realidad del "Jesús histórico" no parece haber logrado integrar la cristología paulina en un molde inicial fundamentalmente sin6ptico. Si bien es verdad que se plantea con seriedad la cuestión del "Jesús histórico," al tratar los textos paulinos esta problemática no parece ofrecer dificultad alguna. Y, de hecho, no se trata explícitamente. 12

Sin embargo, desde otro punto de vista, tanto las imágenes cristológicas de Pablo como su cristología ocupan un lugar muy importante en los tratados recientes. De modo que parece que se da como resuelta la cuestión de la continuidad. Y no sólo la de la continuidad entre Jesús y Pablo, sino también entre Pablo y el resto de autores del Nuevo Testamento. Cosa que no acaba de "atar" porque, si por un lado los evangelios sinópticos parecen haber integrado en sus cristologías lo que se llama "la historia de Jesús," ¿cómo es posible justificar la integración de la cristología de Pablo en un molde que no es el suyo, más aún que parece ser muy disinto al suyo? Para decirlo más provocativamente, ¿cómo se puede enlazar la cristología paulina, que parece haber dejado de lado la "historia de Jesús," con un molde cristológico que parte precisamente de la relevancia del "Jesús histórico"? ¿Qué lugar puede tener la austera cristología paulina en una cristología que parte del tema del reino y de los gestos extraordinarios de Jesús (aspectos prácticamente ausentes en la presentación cristológica de Pablo)? ${ }^{13}$

Ante este status quaestionis, que resulta suficientemente importante en cualquier caso, quisiéramos retomar el tema Pablo-Jesús. Y quisiéramos hacerlo sin demasiadas pretensiones de poder ofrecer aportaciones nuevas o fundamentales. Pero, en cambio, sí quisiéramos tomar buena nota de lo que la investigación del tema nos ha enseñado hasta ahora, y que parece que continuamos olvidando, para 
llevarlo un poco más lejos. Por ello nuestra pregunta va a ser al mismo tiempo fundamental e inevitable, ¿quién es Jesús para Pablo? ${ }^{14}$

\section{El problema del Jesús histórico}

Cuando los discípulos de Bultmann emprendieron una verdadera revisión de las tesis de su maestro en la cuestión del Jesús histónico, no eran plenamente conscientes del grado de dependencia que los ataba todavía a las tesis de su maestro. ${ }^{15}$ Una de las cosas que se ha ido clarificando a lo largo de estos aflos es que la llamada cuestión del Jesús histórico es un planteamiento nuestro que comporta una forma de enfocar el problema que no tiene paralelo ni en los planteamientos del Nuevo Testamento ni en los de los padres de la primitiva Iglesia. Para decirlo con más claridad: el problema de la investigación del Jesús histórico que la llamada New Quest reemprendió con nuevas energías, ni coincide con la confesión eclesial del Deus-homo, ${ }^{16}$ ni acaba de coincidir con lo que podríamos llamar el interés del Nuevo Testamento en Jesús de Nazaret. Esto hay que desglosarlo un poco más porque es uno de los puntos que más interesan para nuestro trabajo.

El conocido "manifiesto" de E. Käsemann, en su conferencia a los colegas de Marburgo en 1953, ya implicaba que la cuestión del Jesús histórico no coincidia con el interés de los autores del Nuevo Testamento por Jesús (sobre todo los evangelios de Marcos y Mateo). ${ }^{17}$ Pero esto no se explicitó con claridad hasta al cabo de unos afios. Porque fue en la respuesta de Kusemann a la dura crítica de Bultmann ${ }^{18}$ donde se formuló claramente el problema: "no es la ciencia histórica la que nos obliga a plantear el problema del Jesús histórico; menos aún (precisamente a nosotros, discípulos de Bultmann) la búsqueda de garantías para la fe: es el kerigma lo que nos obliga a ello." 19

Parece suficientemente claro que han sido necesarios unos cuantos affos para que se fuera clarificando que una cosa es la llamada cuestión del Jesús histórico y otra muy distinta el interés que muestran las obras del Nuevo Testamento en Jesús de Nazaret. ${ }^{20} \mathrm{Si}$ bien es verdad que la cuestión del Jesús histórico es una cuestión teológica, lo es para nosotros que hemos partido tanto de un determinado concepto de historia como de unas posibilidades de investigación que pueden distinguir claramente entre el tiempo de Jesús y el tiempo del Nuevo Testamento. En cambio el Nuevo Testamento no solamente no tiene un determinado concepto de historia (cosa que olvidamos muy a menudo), sino que, además, no puede distinguir entre la propia historia y la historia de Jesús de la misma forma que podemos hacerlo nosotros. ${ }^{21}$

Debido fundamentalmente a esta diversidad de situaciones y planteamientos (y naturalmente a otras razones que no tenemos por qué analizar aquí), el estudio del Nuevo Testamento ha ido girando en torno a un planteamiento mucho más mo'esto y diversificado, ¿qué interés se percibe en diversos documentos neotestaı nentarios por Jesús de Nazaret? O, para decirlo más en consonancia con el mismo Nuevo Testamento, ¿hasta qué punto los diversos documentos neoles- 
tamentarios son conscientes de la problemática implicada en el hecho de que el Jesús prepascual resulta idéntico con el Jesús presente (resucitado)?22

Es en el marco de este planteamiento mucho más limitado que quieren inscribirse estas páginas. En el caso de Pablo resulta casi evidente que si "imaginamos" un Jesús histórico (a quien habremos llegado hipotéticamente a través de la investigación histórica, es decir, fundamentalmente sinóptica), entonces la pregunta sobre si este Jesús se encuentra en los escritos paulinos, es muy poco significativa. Es como si se buscase un núcleo aislado, un recorte momificado. $Y$ naturalmente, sólo pueden aducirse unos pocos textos paulinos que reflejen lo que nosotros "imaginamos" históricamente como Jesús.23 Además, resulta que con este criterio Lodos los demás libros neotestamentarios que no sean los evangelios sinópticos se quedan "cortos." Es aquí donde se percibe con más claridad el fallo metodologico fundamental de la investigación sobre el Jesús histórico (la antigua y la nueva). Hablando neotestamentariamente, el Jesús relevante para la fe y para el cristiano es siempre un personaje del presente. No pertenece al pasado; no puede haber quedado anclado en un pasado que sea como una realidad archivada en la memoria de un ordenador. El pasado, hablando desde un punto de vista biblico, o se hace presente o simplemente desaparece. ${ }^{24}$

El Jesús relevante para la fe y para el seguimiento cristiano no solamente no es nunca (en el Nuevo Testamento) un personaje del pasado, sino que, si queremos hablar con un mínimo de propiedad, el único Jesús real y verdadero para el Nuevo Testamento (en nuestro caso para el cristianismo del Nuevo Testamento) es el Jesús predicado. ${ }^{25}$ Por lo tanto, hablando desde un punto de vista estrictamente neotestamentario, quien tiene la prioridad es el Jesús proclamado como Señor y como Dios. La problemática histórica es neotestamentariamente posterior. Pero también es lógicamente posterior. Porque la prioridad la tiene el Jesús presente, es decir, el Jesús confesado como Señor (como Dios). ${ }^{26}$

Todavía hay que añadir algo más. Si queremos ser mínimamente coherentes con una forma de preguntar que tenga en cuenta la investigación histórica, hay que recordar que la problemática sinóptica es (por lo que sabemos) posterior a la problemática paulina. Según nuestros conocimientos, Pablo ni escribió nunca un evangelio ni parece que consideró necesario narrar la vida de Jesús para predicar la buena noticia (que, como vamos a subrayar más adelante, es el mismo Jesús). ${ }^{27}$

\section{Pablo y el Jesús terreno}

En repetidas ocasiones, a lo largo de estos últimos aflos, se ha propuesto que, si la terminología "Jesús histórico" resulta poco apta e incluso (como acabamos de ver) desfiguradora, la formulación "Jesús terreno" parece ser mucho más cercana al interés del Nuevo Testamento en Jesús de Nazaret. ${ }^{28}$ Es posible que esta propuesta, que yo mismo he suscrito en diversas ocasiones, tenga algo de verdad. ${ }^{29}$ Sin embargo, analicemos la propuesta un poco más de cerca.

En primer lugar, ¿resulta suficientemente claro lo que se implica en la for- 
mulación "terreno"? Pero, además, cuando hablamos de terrenalidad, ¿podemos describir este concepto de forma que resulte asimilable a las diversas propuestas del Nuevo Testamento? ¿No estamos ante una formulación muy "nuestra," es decir, muy abstracta, y muy poco neotestamentaria? He aqui un primer aspecto problemático que presenta suficientes dificultades. Pero demos un paso más. Para Pablo, Jesús ¿puede ser descrito —de alguna forma- como "el terreno"? ¿Encontramos en las cartas de Pablo y su escuela, trazos que hagan patente y subrayen la terrenalidad de Jesús?

Si analizamos las cartas de Pablo con un cierto detalle y las escudrifiamos con el fin de encontrar en ellas algunos datos que subrayen que Jesús queda definido por su condición humana (hay que asumir que esto es, en definitiva, lo que se implica en la "terrenalidad"), sin duda que hallaremos algunos: Jesús es también el Christos kata sarka (Rom 9, 5; cfr. Rom 1, 3-4; pero en cambio no en 2Cor $5,16)$ y, por tanto, le pertenece también de alguna manera la condición humana; Jesús es aquél que ha sido crucificado ex astheneias (cfr. 2Cor 13,3-4), es decir, es aquél que ha participado de la debilidad propia del hombre mortal; Jesús es aquél que ha tenido una agonía, una nelrôsis (2Cor 4, 10-11) que el apóstol lleva en su sóma (cuerpo de Pablo). Por otro lado, tenemos también en las cartas de Pablo una clara referencia al hecho de que Cristo ha nacido de una mujer y ha vivido bajo el régimen de la ley (Gal 4, 4 y también el texto de Rom 8, 3). Dejemos de lado, por el momento, cú́les son los acentos más importantes de estos textos. Sin embargo, podemos preguntamos, ¿no resulta un poco incoherente ir a parar a unos pocos textos, como los que hemos citado (y que podrían ser ampliados), para mostrar que es preciso tener en cuenta la terrenalidad de Jesús en las cartas de Pablo? Este tipo de argumento, ¿no resulta simplemente artificial? Es aquí donde uno se siente siempre no sólo lejos de los relatos evangélicos (en este caso sobre todo de los relatos sinópticos), sino también en otro terreno, donde las cosas deberian enfocarse de otra manera. ${ }^{30}$

Tomemos otra propuesta: en diversos estudios se hace referencia a que las cartas paulinas subrayan también el hecho de la encarnación de Jesús. ${ }^{31}$ Y se aducen textos como el mencionado de Gálatas 4, 4 y también Romanos 1, 3-4 (los cuales se refuerzan a través de textos de la escuela paulina como, por ejemplo, Ef 1, 10 y también el himno de Col 1, 15-21). Pero podemos preguntarnos, ¿estamos ante un tema que Pablo quiere presentar como tal? ¿No se están forzando estos textos para darles un contenido que no tienen? ¿No estamos cambiando los acentos y poniéndolos donde no están? Es patente que estos textos pueden resultar una confirmación de un terma joánico o pueden mostrar una clara consonancia con La presentación cristológica de Hebreos, pero, en cambio, ¿constituyen en sí mismos un trazo fundamental de la presentación de Pablo?

Los ejemplos se podrian multiplicar porque to que se intenta hacer evidente aquf es que el interts que parecen mostrar otros documentos neotestamentarios en la vida terrena de Jesús, en sus gestos y en su condición de ser semejante a los hombres en todo (como dira Heb, excepto en el pecado), no solamente no hacen 
justicia a la presentación paulina, sino que incluso nos hacen perder los acentos fundamentales de esa presentación en un punto tan fundamental como es el que planteábamos al comienzo: ¿quién es Jesús para Pablo? Esta es, pues, la pregunta que hemos de intentar responder. Sólo en el marco de esta pregunta será posible ver cuál es el sentido y cuáles son las dimensiones de nuestro tema en Pablo.

\section{3. ¿Quién es Jesús para Pablo?}

Notemos, en primer lugar, que nuestra pregunta no puede ser "¿quién fue Jesús para Pablo?" No puede serlo porque esta pregunta ya presupone una cierta respuesta. Pero, además, porque los textos paulinos no responderían a esta pregunta ${ }^{32}$ Esto supuesto, hay que afladir que cualquier manual neotestamentario sabe responder a nuestra pregunta: Jesús, para Pablo, es el Mesías muerto y resucitado. He aquí una respuesta no sólo clara, sino también claramente subrayada en los escritos del apostol de los gentiles. No estamos ante una serie de textos aislados, con un sentido dudoso. Estamos ante el verdadero centro de la presentación paulina. No se puede predicar la buena nueva (el euaggelion) sin predicar a Cristo muerto y resucitado. No hay cartas paulinas sin este tema capital. Es en este núcleo de la predicación paulina donde encontramos una referencia inevitable a la muerte de Jesús. Tan inevitable que para algunos la resurrección de Jesús no sería otra cosa que un capítulo del libro de la muerte de Jesús en cruz. ${ }^{33}$

El problema no es, por tanto, si Pablo da importancia a la etapa del Jesús terreno. Lo que podemos preguntamos aquí es más bien si es posible hablar del Jesús resucitado (el Kyrios) sin hablar del Jesús muerto. ¿Tiene algún sentido hablar del Jesús paulino como el Jesús resucitado y constituido hijo de Dios en poder sin implicar en ello la muerte de Jesús y, por tanto, como hemos de ver, su donación de la vida por nosotros? ¿Se puede hablar del Seftor de la gloria sin hablar de la profunda debilidad de la carne, es decir, de la muerte? Estas son las preguntas que surgen en el contexto de las cartas de Pablo. No las que hemos imaginado partiendo de la problemática sinóptica o de una consideración abastracta de lo que hemos llamado "terrenalidad" de Jesús.

Por consiguiente, es preciso acercarse a este núcleo fundamental, porque es aquí donde está la fuerza de las afirmaciones paulinas. Este es el núcleo que debemos analizar más despacio para ver hasta qué punto Pablo ha dejado de lado la realidad (humana) de Jesús de Nazaret

\subsection{La muerte "por nosotros"}

No es preciso apelar a la problemática de Lutero y de la reforma para constatar que la muerte de Jesús resulta relevante para Pablo, no en la medida que aconteció en la profunda vallis historiae. Si la muerte de Jesús en la cruz es fundamental para Pablo, ello se debe a que alli se da la salvación "para (y por) nosotros." Lo que se encuentra afirmado en cualquier tratado de teología paulina resulta patente 
con sólo ponerse en contacto con los escritos más importantes de Pablo: Jesús muere en la cruz para salvamos, lo cual se hace explícito a través de la resurrección. Como se ha dicho y repetido muchas veces, el interés de Pablo por Jesús es un interés marcadamente soteriologico, porque sin muerte en cruz no hay salvación. ${ }^{34}$

Ya es bien sabido que hay muchos textos paulinos centrados en esta afirmación fundamental y que resultan muy familiares. No vamos a repetirlos aquf, pero uno de ellos resulta tan importante que hay que recordarlo: 1Corintios 15. Entre las muchas cosas que se pueden subrayar a ralz de este texto, hay una que nos interesa especialmente hoy porque no se acostumbra a resaltar muy a menudo: ¿qué sentido tendráa la larga argumentación de Pablo en este capítulo si la muerte de Jesús fuera un suceso de otro mundo? ¿Hasta qué punto no depende todo el largo y enrevesado argumento de Pablo en 1 Corintios 15 del hecho cierto e innegable de la muerte de Jesús?35

Subrayemos, además, un segundo aspecto. Como es bien sabido la resurrección de Jesús es para Pablo (sobre todo en este texto) un suceso de Dios respecto no sólo de Jesús, sino también de codos los hombres. En Jesús todos estamos incluidos: él es el nuevo Adán, el primogénito. ${ }^{36}$ Recordemos aquí algo muy relevante, ¿qué sentido tendráa esta reflexión fundamental de Pablo si no se da por supuesto que nosotros podemos participar de la resurrección de Jesús precisamente por el hecho de que él ha participado de nuestra muerte?

\subsection{La vida por nosotros}

Resulta de sobra conocido que Jesús, para Pablo, es el que se ha entregado, el que ha dado la propia vida. En uno de los textos más inspirados de la literatura paulina, Pablo intenta presentar este gesto inconmensurable de Jesús. Se trata de un texto bien conocido que conviene, sin embargo, recordar.

Fijénse bien en esto: cuando éramos incapaces de todo, precisamente entonces Cristo murió por los impios. Ciertamente con dificultad uno se dejarfa matar por una causa justa; por una buena persona quizá alguno afrontaria la muerte. Pues bien, Dios demostro el amor que nos tiene al morir Cristo por nosotros cuando aún éramos pecadores... (Rom 5, 6-8).

La razón de ser de este texto está precisamente en que no hay imagen alguna que pueda expresar el hecho desconcertante e imposible de la muerte de Cristo. Lo que Pablo quiere decir con este texto es que la muerte de Cristo por nosotros rompe todos los esquemas. ${ }^{37}$ No hay posibilidad de expresarla adecuadamente. Se trata de un hecho imposible de enmarcar en los ejemplos de la vida de cada día. Por ello resulta también difficil encontrar imágenes que ilustren este doble aspecto: expresar el valor salvifico de la muerte de Jesucristo y, al mismo tiempo, hacerla igual a nuestra muerte. El argumento de Pablo es lógicamente inverso: si ésta es la muerte de Jesucristo, nuestra muerte puede también ser la suya (cfr. los conocidos textos de Rom 6, para poner un ejemplo especialmente claro). Pero en- 
tonces la realidad de la muerte de Jesucristo tiene una prioridad cristológica que no admite el acento en que la muerte de Jesucristo ha sido como la nuestra El argumento de Pablo tiene otro orden. ${ }^{38}$

Profundicemos un poco más en el tema. La muerte de Jesús en cruz no es salvífica por una fuerza que acuía arbitrariamente. No lo es tampoco porque Dios lo ha decretado al margen de lo que Jesús ha hecho. Lo es porque es el resultado de una vida vivida por los hombres. Esta es la razón por la que resulta en verdad salvífica. ${ }^{39}$ Por tanto, en la muerte de Jesús está la vida de Jesís par nosotros, porque morir por nosotros significa fundamentalmente dar la vida por (para) nosotros, es decir, amar. ${ }^{40}$ Lo que nos salva en la muerte de Jesús es la fidelidad de Jesús a Dios, que manifiesta la fidelidad y la benevolencia de Dios respecto de los hombres. En la medida que esta fidelidad puede ser vivida por nosotros, en esta medida la muerte de Jesús es salvación.

\subsection{La realización de un proyecto y de una trayectoria}

Todo esto enlaza con lo que llamamos a menudo esquema de historia salutis. No vamos a detenemos a polemizar contra un modelo teologico que puede reconocerse en el pensamiento de Pablo desde siempre. Lo que sí quisierramos remarcar es que el esquema de lo que llamamos la historia de salvación no es negado (de hecho Pablo lo utiliza entre otras cosas para mostrar que Israel no está irremediablemente perdido), pero, en cambio, no se utiliza directamente para iluminar la soteriologfa paulina que se encuentra mucho más enraizada en la línea de la tipología y de la alegoría ${ }^{41}$ En este sentido la pregunta, ¿quien es Jesís para Pablo?, no tiene una respuesta en estricta dependencia de la historia de salvación, sino que oscila directamente sobre un esquema teológico que parte de la confesión de Dios como el creador y no necesariamente como director de la histaria ${ }^{42} \mathrm{La}$ confesión teologal de Pablo es la de un Dios que puede crear y recrear. Si Jessís nos salva es en definitiva porque en él se hace presente un Dios que es capaz de sacar vida de la nada o también de sacar vida de la muerte. ${ }^{43}$

Hasta aquí un esbozo de lo que se puede decir a grandes rasgos sobre la doctrina de Pablo en tomo a la cuestión de Jesús de Nazaret y de su papel en las cartas paulinas. Uno puede preguntarse con razón si el breve resumen que antecede no resulta muy conocido. Y la respuesta es que sf, que verdaderamente lo es. Pero hay que affadir inmediatamente un aspecto que no se subraya tanto a nivel de la presentación de la doctrina de Pablo como en el mismo enfoque hermeneutico con que conviene leer sus cartas: que la doctrina de Pablo no puede desligarse de su vida Para decirlo de otra forma: sólo a través de la vida y de la experiencia de Pablo será posible captar la verdadera dimensión de su presentación teologica 44 Esto es lo que quisiéramos analizar un poco más, siempre dentro del marco de nuestro tema, para sacar de ello implicaciones de mayar importancia

\section{Pablo y Jesús}

Comencernos con una reflexión a nivel general. Las cartas panlinas (en este 
caso nos referimos a las cartas auténticas y no necesariamente a toda la literatura paulina) son documentos únicos en el Nuevo Testamento. 45 En ellas se halla el testimonio directo de Pablo y la manera concreta como ha vivido su transformación. Son retazos de la misma vida de Pablo. Para Pablo escribir es parte de su vida (cfr. 2Cor 3, 2-3). Es aquí donde tenemos un primer acento capital para nuestro tema: Pablo habla de su vida de cristiano en térninos de una verdadera nueva creación, los textos son bien conocidos. ${ }^{46} \mathrm{Y}$ lo que da a entender es que ha habido una novedad radical en su vida. Esta novedad radical se llama Jesucristo, asl, globalmente. Conviene valorar los aspectos de esta novedad radical.

En primer lugar, hay que recordar que Pablo no es un resentido respecto de su pasado fariseo. No hahla de esta época de vida con resignación o con agresividad. Sin embargo, los textos paulinos están marcados por la convicción de la vaciedad total del régimen de la ley. Es en este marco donde conviene subrayar que Pablo no podía haber salido con sus propias fuerzas del régimen de la ley. ${ }^{47} \mathrm{La}$ novedad radical de la vida en Cristo le ha de haber venido de fuera. Y, ciertamente, no de las fuerzas humanas (de aquí el sentido tan radical de los textos de Gálatas sobre la no deductibilidad del objeto de su experiencia y de su predicación ${ }^{48}$ ); por consiguiente, Jesucristo ha sido vivido por Pablo en la línea de la novedad radical: la de aquello que ha venido de Dios como novedad radical, es decir, lo que ha sido creado en él. 49

Siguiendo la lógica de nuestro argumento, si la explicación paulina de su radical transformación está necesariamente ligada a Jesucristo, también en Jesucristo se ha de dar la justificación de un nuevo estilo de vida basado precisamente en la libertad. Una vida nueva basada precisamente en la liberación del régimen de las obras de la ley ha de tener un punto de referencia bien claro y definido. Este punto de referencia es Jesucristo. Por tanto, en este contexto de novedad, recreación, gratuidad, ¿cuál es el contenido de Jesucristo para Pablo? Lo vamos a analizar a través de una serie de formulaciones paulinas.

Dios revelo a Jesucristo a Pablo. Es aqui donde parece lógico hacer referencia al conocido texto de la apokalypsis Iesou Christou (Gal 1, 12; cfr. 1, 15-16). Muy a menudo se equipara este texto con el de 1Corintios 15, 3-7 y ambién con 1Corintios 9, 1-2 (cfr. 2Cor 12, 1-5); y es muy probable que en algún sentido haya un acercamiento innegable entre este conjunto de textos. ${ }^{50}$ Sin embargo, el texto de Gálatas 1, 12 habla de la realidad de Jesucristo con una globalidad y una definitividad que no tenemos en los otros textos, 51 porque esa carta está justificando un determinado estilo de vida que Pablo ha visto nacer en sí y que estŕ inculcando a los gálatas. Y la apokalypsis lessou Christous2 no solamente acentúa la gratuidad de la justificación y la manifestación del resucitado, sino también el sentido y el aire de la vida de Pablo frente a otras formas de entender y practicar la fe. ¿De dónde ha sacado Pablo este estilo de vida? Es un estilo de vida totalmente nuevo, diferente, no deducible ni de los presupuestos de Pablo (bien sean las obras de la ley, bien un cristianismo antioqueno) ni tampoco de la actitud fundamental del grupo de los doce. Por consiguiente, este estilo de vida 
basado en la libertad sólo puede haber sido inducido en Pablo a través de Jesús: de la vida de Jesús (y también de su muerte), porque no se trata de justificar sólo una determinada praxis ( $f r$. Rom 15, 3); estamos ante aquello que da razón de la raíz última por la cual Pablo vive como vive. Hay que tener en cuenta aqui, además, que lo que lamamos justificación por la fe, al margen de las obras de la ley, más bien llevaria a una existencia agradecida con un peligro grande de convertirse en paralizante. En cambio, Pablo subraya toda una vertiente apostólica: "me reveló a su hijo para que lo anunciara a los gentiles" $(\mathrm{Gal} 1,16)$. Esto hemos de verlo un poco más despacio.

La actuación de Pablo como servicio. Resulta muy conocido que la espiritualidad paulina es una espiritualidad de servicio: doulos Irsou Christou. Y es también claro que la inspiracion profética de esta autodescripción es cristologica ${ }^{53}$ Por tanto, Pablo intenta vivir a la luz de la forma como Jesús ha vivido. No tiene otro punto de inspiración. No hay ningún otro modelo con que identificarse: sólo con Jesús. Aqur hay que recordar los muchos textos que hacen referencia a esta realidad fundamental: "para mi el vivir es Cristo" (Fil 1, 21; cfr. Gal 2, 20; $2 \operatorname{Cor} 4,7-11$, etc.). Naturalmente que la vida de Jesús es también la vida del Seffor presente, pero nunca al margen de la forma concreta como Jesús ha vivido. Par ello, Pablo lleva en su cuerpo la "agonía" (nekrosis) de Jesús (2Cor 4, 10-11), el morir de Jesús (que, naturalmente, no puede ser el morir del hijo de Dios ya exaltado), las marcas del sufrimiento de Jesús (Gal 6, 17), la debilidad de la existencia carnal de Jesús (ffr. Rom 8, 3 y 2Cor 13-3-4).

Por un lado, por tanto, Pablo se define por dentro a traves de Jesús. Pero, además, este ser doulos lesou Christou no acaba de dar toda la dimensión de quién es Pablo: también es apostolos o más explícilamente llamado a ser aposiolos. ${ }^{54}$ La salvación por la fe al margen de las obras de la ley no conduce a Pablo a una espiritualidad intimista o paralizante. Lo conduce más bien a vivir predicando y procurando ganar a los que pueda. Esta espiritualidad de servicio apostólico, que constituye la definición más profunda de Pablo, solo se explica a la luz de un destino (janagke!) asumido. 55 Pablo no subraya la autonomía de la vida espiritual, sino más bien la fuerza del evangelio que lo hace libre para el servicio y le permite amar porque se siente amado (1Cor 9, 15-19). La motivación cristológica de su apostolado no estí contra la inspiración profética de su tarea Más bien al reves. 56

La ley de Cristo (Gal 6,2). Un último texto nos iluminara la espiritualidad paulina: es un texto que, a primera vista, parece muy poco adecuado porque habla de la ley de Cristo (Gal 6,2; cfr. ennomos Christou en 1Cor 9, 21). ¿Qué sentido tiene esta formulación paradojica? ¿Cuál es la ley de Cristo? Porque hay que recordar que, para Pablo, Jesuis no es ley, sino más bien buena noticia. ${ }^{57} \mathrm{~A}$ la luz, tanto del contexto de Gálatas 6, 2 como de las referencias a llevar unos las cargas de los otros, no queda la menor duda de que Pablo se está refiriendo a la ley del amor (cfr. Rom 15, 3 y 13, 8-10, textos retomados de Gal 5, 14, que a su vez marca el contexto de 6,2$){ }^{58}$ Lo que ocurre es que la expresión "ley" resulta 
sorprendente. Pero no lo es tanto si tenemos en cuenta el contexto estrictamente polémico de la carta a los Gálatas, en el cual al hablar de llevar unos las cargas de los otros incorpora la sacralidad de la ley, precisamente porque ha sido la forma de vivir del mismo Jesús ( $f r$. el énfasis en el "nacido bajo la ley" de Gálatas 4, 4 y el conocido texto de 2Cor 12, 9-10). Por consiguiente, la ley de Cristo ha de ser necesariamente la manera concreta como Cristo ha vivido, es decir, amando y dando la vida.59 Esta es la única "nomna" o "ley" para Pablo. No se trata, por tanto, de una "ley" que viene de fuera, se trata más bien de una ley que viene de dentro ( $c f$ r. la ley del espíritu de Rom 8, 2-3). Pero no estamos ante una experiencia intimista de Pablo. La realidad de Jesucristo que se le ha dado a conocer a Pablo (el apokalypsis, cfr. supra) y que éste presenta como punto de referencia de su actuación y de su actinud frente a otros cristianos, no puede ser algo puramente personal e intransferible. Ha de ser una realidad que también otros puedan conocer y seguir (ipor lo menos los gálatas!). Lo que inspira y, en el fondo, constituye el contenido fundamental de su actuación es Jesús y su actuación. Recordemos que, en la carta a los Filipenses, Pablo les dice que el único punto de referencia para guiar sus pasos está en la actitud fundamental de Jesús de Nazaret (Fil 2, 3-4).

\section{Reflexiones finales}

Según lo que hemos visto y repasado, el tema Jesús-Pablo no está determinado por la cuestión de si Pablo conoció personalmente a Jesús de Nazaret o no. ${ }^{60}$ Pero tampoco por la pregunta sobre el tipo de información acerca de la historia de Jesús que podríamos sacar de los escritos paulinos si no tuviéramos otros documentos del Nuevo Testamento.61 Hay que affadir, finalmente, que tampoco resulta decisivo que haya doctrinas entre los adversarios de Pablo que resulten condicionantes del tipo de tratamiento que hemos planteado en este trabajo (para poner un ejemplo bien conocido, la presentación cristológica de Pablo en 2Cor 10-13 no está sólo condicionada por la cristología de aquellos a quienes Pablo llama "superapóstoles"). ${ }^{62}$

Hasta aqui unas conclusiones negativas. En un sentido más positivo, de las consideraciones y del argumento que preceden se podrían sacar unas cuantas consecuencias. Vamos a subrayar dos que parecen suficientemente significativas.

En primer lugar, lo que se refiere a nuestra pregunta inicial: la relación entre Jesús y Pablo. Parece que ha quedado suficientemente claro que, según como se formule, podría tratarse de una pregunta nuestra. Por consiguiente, si queremos enlazar con la temática y con los esquemas paulinos debemos de transformarla un poco a fin de dar con la respuesta adecuada. La pregunta que debemos formular es: ¿quién es Jesús para Pablo? Es en este contexto donde enlazamos con la problemática paulina y con la realidad del mismo Jesús de Nazaret dentro del horizonte de Pablo.

Lo más importante que se deduce de este cambio de enfoque es la renuncia a un esquema objetivante que haría de Jesús una magnitud separable de Pablo. Y 
ello no es posible. No lo permiten ni los textos ni la misma experiencia paulina reflejada en los textos. No se puede hablar de Jesús sin hacer patente la atadura esencial que nos remite constantemente a la vida de Pablo, a su experiencia de la gratuidad, a la sorpresa fundamental de su vida: lo que nunca fue posible, se ha hecho presente a causa de Jesús. Tenemos aquí un criterio hermenéutico fundamental: el testimonio de Pablo (que en el fondo teológicamente es una mediación) resulta un medio de acceso del cual no es posible prescindir. ${ }^{63}$ Sólo podremos averiguar quién es Jesús para Pablo si tenemos en cuenta que Pablo sólo se explica desde Jesús y, por lo tanto, que hay aquí una imbricación inextricable. Si para Pablo "vivir es Cristo" Y si su vida (que es un morir poco a poco cfr. 2Cor 4, 10-11) manifiesta la vida de Jesús, entonces Jesús y Pablo no pueden ser dos magnitudes separables, porque, en el fondo, la respuesta a nuestra pregunta es no solamente que sin Jesús no hay Pablo, sino por encima de todo que sin Pablo no hay Jesús. Para decirlo con más exactitud, sin Pablo Jesús no sería lo que es. ${ }^{64}$

Pero entonces, y esta es una ulterior reflexión sobre este primer aspecto, resulta que el lugar donde encuentra eco nuestra pregunta es en la manera concreta como Pablo vive su vida. O, si se quiere, en la espiritualidad de Pablo, porque todo el vivir de Pablo es el vivir, morir y resucitar de Jesús. Es todo el misterio de Jesús el que conforma y estructura la vida de Pablo. De manera que sin la vida concreta de Jesús difícilmente podríamos comprender por qué Pablo vive como vive y por qué se siente movido al servicio apostólico de la manera como lo lleva a cabo. La inspiración de la vida de Pablo es el vivir de Jesús. La ley (las obras de la ley) no podían hacer surgir una existencia en libertad que sólo se apoya en la fuerza de Dios que actía precisamente en la muerte de Jesús (cfr. 2Cor 5, 19-21), pero que actúa porque Jesús ha vivido de una forma determinada. Por ello el interés de Pablo por Jesús se ha adentrado en Jesús, ha ido hasta las motivaciones y a la forma concreta como Jesús enfocó su vida y su muerte. No se trala de rehacer acciones o palabras de Jesús, se trata de revivir actitudes y el enfoque fundamental de Jesús, tanto de cara a Dios como de cara a los hombres. En esta línea Pablo ha ido más lejos que otros autores del Nuevo Testamento. Que la formulación "imitación" que se encuentra en algunos textos paulinos (por ejemplo, en 1Cor 11,1 o en Fil 3, 17) exprese de forma suficientemente clara lo que venimos describiendo, no es algo que haya de preocupar. De hecho, Pablo habla de su vida en Cristo de muchas maneras y apelando a olras muchas imágenes. Lo que Pablo quiere comunicar es, en el fondo, mucho más osado que lo que viene subrayado con la categoria narrativa del "seguimiento." Porque Pablo ha osado meterse dentro de Jesús (o se lo ha encontrado dentro) y ha intentado descubrir cuál ha de ser la actitud fundamental del hombre, si quiere ser hermano del mismo Jesús (y de los demás) e hijo de un mismo Padre. ${ }^{65}$ Por ello, las referencias a Jesús que interesan a Pablo son las que definen la vida de Jesús por dentro: la mente de Cristo (1Cor 2, 16), las entraflas de Cristo (Fil 1, 8), la actitud interior de Cristo (Fil 2, 3-4), la bondad y misericordia de Cristo (2Cor 10, 1), el amar de Cristo (Gal 2, 20), su entregarse (Ibid). Pablo subraya aspectos y trazos que definen a Jesús en su ser más íntimo: la fe de Jesús (Rom 3,23), el 
no complacerse a sí mismo (Rom 15, 3), su acogida cálida (Rom 15, 7), su profunda debilidad (2Cor 13, 3-4), su condición humana asumida (Fil 2, 6-8). En este contexto las expresiones "vida de Jesús" (sobre todo en 2Cor 4, 7-11) y muerte de Jesús (passim) no son referencias puntuales, más bien incluyen toda una forma de vivir y de asumir la muerte. Esta globalidad cristologica es la que caracteriza la realidad de Jesús confesado como hijo de Dios en las cartas de Pablo.

En este conjunto de datos hay un matiz que debemos subrayar. La forma concreta como Pablo ha vivido su experiencia cristológica fundamental lo lleva a vivir "fuera de sí," descentrado. Este descentramiento hace que su vida esté "escondida en Cristo con Dios" (cfr. Col 3,3). No es que este aspecto constituya una novedad tan radical. El hombre de la tradición bíblica sabe que el centro de la vida no es él mismo, sino Dios. Pablo, en este sentido, ha podido sustituir a Dios por Jesucristo, porque Jesucristo pertenece, sobre todo después de la resurrección, a la esfera de Dios (cfr. Rom 1, 3-4). Ahora bien, esta "vida de Jesús" incluye necesariamente su vida moral. Al fin y al cabo sólo en la vida mortal de Jesús se encuentra el punto de enlace con la forma como Pablo vive su vida (cfr. Rom $8,3)$.

Hasta aquí una somera presentación de lo que podriamos llamar la "recuperación" de la vida mortal de Jesús por parte de Pablo. No es necesario advertir que estamos en un mundo muy distinto del de los evangelios sinópticos (e incluso de Juan y Hebreos). Pero aquí está precisamente el interés de la aportación de estas páginas. De una forma bien distinta a otros autores del Nuevo Testamento Pablo no sólo tiene en cuenta la vida mortal de Jesús, sino que ella precisamente constituye el centro de su propia vida: el cristiano tiene la mente de Cristo, los sentimientos de Cristo, vive la vida de Cristo, ama como él, acoge como él, se adapta a todos, vive entregado a los demás... precisamente por ello Cristo habla por medio de Pablo (2Cor 13, 3; cfr. 2Cor 2, 17; 12, 9).66 Dado el mundo cultural de Pablo, equipado con un instrumental intelectual más fuerte y elaborado que el de los sinópticos, nos ha de resultar en muchas cosas mucho más cercano a nuestras categorías occidentales. Es más apto para esquemas menLales más sofisticados. En cambio la presentación narrativa de los sinópticos llega más fácilmente a medios culturales más directos y, desde un punto de vista intelectual, menos sofisticados. Lo cual no quiere implicar en modo alguno que el mensaje de Marcos, para poner un ejemplo, no tenga una profundidad y agudeza extraordinarias. ${ }^{67}$ El pluralismo del Nuevo Testamento en este punto central ("¿quién es Jesús?") nos enriquece cada vez más.

Como segundo punto de esta conclusión quisiéramos recoger lo que hemos insinuado al comienzo respecto de la cristología. Y aqui conviene decir algo un poco incisivo. Siguiendo el hilo de nuestra argumentación, parece que Pablo, su vida y su experiencia, habrian de tener cabida en la reflexión cristológica cristiana. Pero no como un punto de referencia extrínseco, sino más bien como contenido esencial, lo cual no resulta tan osado o extrafio como a primera vista pudiera 
parecer. Lo que queremos decir es que, al tratar o aducir los textos paulinos, habria que tener en cuenta el sentido que les conliere el hecho de que hayan sido formulados por Pablo como reflejo de la propia experiencia cristológica. En el fondo, como decíamos más arriba, la vida de Pablo es la vida de Jesús. No solamente porque los textos paulinos lo dicen explícitamente. Si lo dicen es porque Jesucristo, para Pablo, es el contenido último de su vida. Después de Jesús no hay nada más. No hay otra instancia que justifique que se puede vivir de este modo. Sólo la vida de Jesús, que ha sido el hermano mayor, el que ha abierto camino (1Cor 15, 20; cfr. Heb 12, 2). Es posible que tengannos aquí una salida a la polémica en torno a una interpretación cristológica de los escritos paulinos como contrapuesta a una interpretación antropológica. ${ }^{68} \mathrm{La}$ realidad de la vida de Jesús es, en último término, una clave de lectura fundamental tanto de las cartas paulinas como de la misma experiencia de Pablo. Este es un aspecto que no podemos desarrollar más aqui, pero tiene una consecuencia que debemos por lo menos mencionar.

¿Hasta qué punto el comar en serio la mediación de Pablo no nos llevaría a una teología mucho más enlazada con la espiritualidad y con la experiencia cristiana? El divorcio entre teologia y espiritualidad que se consumó a partir del siglo XIII, ¿no viene en gran parte de no haber tomado con seriedad las mediaciones de los autores del Nuevo Testamento? Parece que, por lo menos en el caso de Pablo, no podemos seguir considerando su incidencia en nuestra reflexión teológica en términos de "formulaciones doctrinales." Lo que más interesa es su experiencia, testimoniada directamente en sus escrilos. Pero esta realidad experiencial cristiana queda normalmente al margen de la reflexión teológica, la cual sigue, en la utilización del Nuevo Testamento, los caminos que le marcó la célebre distinción entre "sentido literal" y "sentido espiritual." ${ }^{\text {"69 }}$ En este caso, ¿dónde dar con el posible enlace entre la experiencia que vive y aletea bajo los textos y nuestra reflexión teológica? Creo que nuestro camino es aquí lodavía largo y complejo. Sin embargo, hay que comenzar a recorrerlo pronto, no sea que perdamos el hilo cristológico fundamental de los textos del Nuevo Testamento. En el caso de Pablo este parece ser un peligro muy real. ${ }^{70}$

\section{Noles}

1. No he encontrado ningún trabajo en castelinno que trate el tema. Tal vez exista alguno, pero ni conale on las bibliografles ni aparece en balances recientes: F. Pastor, "Acercemiento a Pablo: panonme actual de los estudios punlinos," publicado en Sal Terrae, 72 (1984) 377-384; hay cambien un interesante balmes bibliografico en la cuidade introducción de M. Legido al libro de G. Eichholz, El evangelio de Pablo. Esbozo de ieologia pawina, Selemanca, 19TI, Pp. 14-15 y las notes de les pp. 24-26.

2. Por ejemplo, V. Fumish, "The Jesus-Paul Debate: Fran Beur to Bultmann," BJRyL 47 (196465) 342-381. Pero tmbien se encuentren restrmenes de esta historia en los copplulos introductorios de diversas manograflas: J. Blenk, Poulus und Jesus. Eine theologische Grundlegung, München, 1968, cap. 2: "Das Problem 'Pulus und Jesus' in den jilngeren Fonschung," pp. 61132; E. Jingel, Paulus und Jesus. Eire Unsersuehung 210 Prdzisienung der Frage nach dem Urspreng der Chrisfologie, HU 2, Tübingen, 1962, pp. 5-16. 
3. La aporiación del articulo de F. Chr. Baur estí resumida en el trabajo de Fumish citado en la nota 2 y es bastante anterior (1831) a la formulación de su conocida tesis sobre el lugar de Pablo en el desartollo del eristianismo primitivo en base fundamentalmente hegelinna (Vorlesungen über newestamentliche Theologie, Tübingen, 1964, reedindo recientemente). El unbajo de Wrede (Poulus, 1905) es suficientemente conocido y la aporiación de A. Schweitzer (wanlo en Gesehichse der paulinischen Forschurg de 1904 como en Die Mystik der Apostel Paulus de 1905) marco un verdadero hito en los estudios paulinos.

4. Esta cuestión, como resulta de sobra conocido, fue un locus communis de lo que se viene llamando teología liberal de la segunda mitad del siglo XIX.

5. Además de sus comentarios al tema en ls Theologie des neuen Testaments, Tübingen, 1968, pp. 188-190, conviene tener en euenta sus contribuciones espectlicas al tema: "Die Bedertung des geschihctlichen Jesus für die Theologie des Paulus," Glouben und Verstehen I. Tubingen, 1933, Pp. 188-213 y también "Jesus und Paulus" en la obre Jesus Chrisus im Zeugnis der heiligen Schrift und der Kirche, München, 1936, PP. 69-90. Hay que tener en cuenta, ademśs, los trabajos que citarnos más adelante, nou 18.

6. Por ejemplo, W. Schmithals, "Paulus und der historische Jesus," ZNW 53 (1962) 145-160 y tambien H. Braun, "Die friuhe Christologie," ZTK 63 (1966) 145-159.

7. De una forma especialmente subrayada en la obra de E. Gütugemans, Der leidende Apostel und sein Herr, Gbutingen, 1966. Con todo el influjo de Bultrmann en este caso es muy nouble y se puede percibir claramente en sus seguidores, especialmente en los trabajos de E. Fuchs, G. Ebeling y II. Conzelmann, efr. la nota 20 infra.

8. Vease las obras y autores cilados en la nola anterior, a los cuales se podra afiadir el trabajo de Jüngel, cilado en la nots 2.

9. Aparte de la obra de J. Blank, citada en la noca 2 supra, se puede cansular el interesente (e independiente) trabajo de G.N. Stanton, Jesus of Nazareth in New Testament Preaching, SNTS MS 27, Cambridge, 1974, especialmente pp. 86-116.

10. Para expresarlo con palabras de un tenaz investigador del tema, la pregunta es si "Pablo toma seriamente la realidad del hombre Jesús o si mis bien no se acercan sus afimaciones a formulaciones muy cercanas al docetismo," W. G. Kürnmel, "Jesus und Paulus," en su obra Heilsgeschehen und Geschichse, Marburg, 1965, pp. 81-106 (hay que recordar que este trabajo se remonts a una conferencia tenida en 1939 y publieada por primera vez en 1940); en el mismo volumen hвy our contribución con el mismo útulo del anto 1964 (cfr. ibid., pp. 439-456). Sin embargo, uno se pregunta si el problema de la cristologla paulina es el docetismo o más bier. dada la poca acentuación de lo que llamamos la pre-existencin de Jesús, el adopcionismo. De hecho la relectura de la muerte de Jesús a la luz de la resurrección apunia mís bien a una "instalación" de Jesús como Sertor después de la resurrección. El nombre de "Kyrias" otorgado a Jesús a partir de la resurrección (Fil 2, 9-11; $f$ f. Rom 1, 3-4) parece conferirle uma función que no tenía. En cualquier caso la nomenclatura empleads ("docetismo," "adopcionismo") no deja de ser anacrónica.

11. Así resume la problemática Pablo-Jesús G. Bomkamm, en su obra Pablo de Tarso, Salamanca, 1979. pp. 291-302 (original de 1969). La problemática de la continuidad entre Jesús y Pablo ha ocupado un lugar muy imporante en el seno del tema que hoy tralamos. Un enfoque a la vez interesante y profundo en E. Jilngel, o. c., pp. 263-284.

12. No parece que sea necesario subrayar que este es un unzo mury cancieristico de las cristologín contemporaneas. Sin embargo resulta especialmente sorprendente que las cristologins de América Latina no hayan integrado este terne, a pesar del ensayo muy merilorio de J.L Segundo, El hombre de hoy ante Jesís de Näzaret, vol. I. 1, Madrid, 1982, pp. 287-535, especialmente Pp. 287-304 y 430-448. El sugerente trabajo de G. Gutiérrez, Beber en su propio pozo, Salamanca, 1984 no pretende llenar este vaclo. VÉase tambien la nota 67 de este trabajo.

13. El problema que todo esto plantea no es meramente acadénico o formal. Porque los peligros de una reflexión cristológica que se alimenka de un molde ontológico ( $y$, por unto, en este caso también epistemologico) ajeno al Nuevo Testamento san mucho más profundos de lo que pueden parecer a primera vista. El tema tiene unas ralces hemenéuticas que superan los límites inevitables 
de un trabajo como este. Pero no hay que perder de vista el horizonte bíblico en que debería moverse una reflexión teologica que tiene corno punto de referencia el Nuevo Testarnento como mediación que no puede tomarse a la ligera.

14. Esta pregunia un sencilla y directa constituye, como tal, el cristianismo. Y deberfa replantearse continuamente de modo que a través de la misma el cristiano alcance el núcleo úlimo de su identidad.

15. Probablemente estamos todos codavia dernasiado condicionados por la historia y no solamente por una hisloriografía positiva que ha marcado hondamente los estudios criticos neotestamentarios desde el comienzo, sino también por la monstruosa sistematización de Hegel que nos aplasta. Un primer ejemplo bien conocido lo tenemos en la escuela de Tubinga (F. Chr. Baur). Pero la interpretación actual del Nuevo Testamento depende todavia mucho de este tipo de sistematización. Para poner un ejemplo: ¿sería muy audaz y se prestaría a ser interpretado como sarcasmo decir que Bujtunann está profundamente marcado por una problemática "historicista"? La problemática hemenéutica que Bultumann planté muy crudamente, ¿no tiene una importancia mucho mayor? De hecho, la escuela de Bulumann derivó a una hemenéutica muy seria que todavia no hemos estudiado en todas sus dimensiones.

16. Esta afimmación debería matizarse más de lo que aqul es posible. Como dice $F$. Hahn, la temática del "Jesús histórico" visıa a través del interts del Nuevo Testamento en Jesús de Nazaret tal vez no sea tan distinta de la confesión del Deus-homo: "Methodologische überlegungen zur Rück Jrage nach Jesus," en la obra editade por $\mathrm{K}$. Kertelge, Rüchfrage nach Jesus, QD 63. Freiburg-BaselWien, 1974, pp. 11-17, cita de la p. 57.

17. Publicada por primera vez en 1954. Ahora tenemos traducción castellana: "El problema del Jesús histórico," en la obra Ensayos exegdricos, Salamanca, 1977, pp. 160-189. Dar una minima bibliografia del tema del Jesís histórico no cae dentro de los objetivos de este trabajo; sin embargo, uno de los trabajos pioneros del tema ha sido poco conocido. Se trata de una conferencia de N.A. Dahl, tenida en 1952 y publicada poco desputs: "Der historische Jesus als geshichtswissenschafliches und theologisches Problem," KD 1 (1955) 104-132.

18. La crítica de Bulemann en forma de conferencia pronunciada en la Academia de Ciencias de Heidelberg en 1959, se public6 el año siguiente: "Das Werhältunis der urchristlichen Christusbotschaft zum historischen Jesus," Sizzunsberiche v.d. Heidelbergische Akad. Wiss., Phil.-hist. Klasse, 1960. La respuestu de E. Käsemann se publiơ en 1964: "Sackgassen im Streit un den historischen Jesus," Exegetische Versuche und Besinnungen, vol. II, Gouttingen, 1964, pp. 31-68. Hay que recordar que Butumann se sinti6 obligado a contestar brevemente: "Antwort an $\mathbf{E}$ Käsemann," publicado en Glauben und Verstehen IV, Tübingen, 1965, pp. 190-198.

19. E. Käsemann, "Sackgassen," p. 66.

20. Este es un punto capital de nuestro trabajo que no podemos explicitar más aqul, pero que conviene por lo menos citar: al ir centrando la investigación sobre el Jesús histórico en los textos del Nuevo Testamento y al intentar dar más con su talante que con la información que puedan proporcionar acerca de la "historia de Jesús," el probleme se ha ido decantando más sobre el hecho hermencutico que sobre la investigación historica. En esta linea los discipulos de Bulumann han hecho una aportacion verdaderamente interesante, al subrayar la necesidad de una interpretacion "existencial" de los textos (H. Conzelmann en el artículo Jesus Christus del RGG III [Tubingen, 1959] 619-653; E. Fuchs, Zw Frage nach dem historischen Jesus [Ges. Aufs. ii], Tübingen, 1960; E. Ebeling, Wort und Glaube, Tubingben, '1967). E. Fuchs y E. Ebeling se han inclinado por un análisis del lenguaje. En este sentido, cuando hablan de la uransformación del fenómeno del Jesús histórico en un Sprachereignis o en un Worigeschehen (cfr. también lo que dice E. Jüngel, en la obra cilada en la nola 2, supro) han ido más lejos de lo que decimos aquí, pero su contribucián deberia ser tenide en cuenta en la medida que ponen el acento en el hecho hermentutico y no en un historicismo trasnochado.

21. Esto ya lo dejaba entrever J. M. Robinson en su obre The New Quest of the historical Jesus, SBT 25, London, 1959, pp. 26-32 ("The ambiguous tem historical Jesus"'). Un planteamiento mucho más, crítico lo tenemos en el trabajo de F. Hahn cilado supra en la nokn 16. pp. 60-63.

22. Este interts diversificado del Nuevo Testamento por Jesús lo he intentado ilustrar en diversas aportaciones que se cilan equi como ejemplo de lo que se implica: "Motivacions èriques de la 
1Jn: in 1Jn i el Jenus historic," publicado en RCeT 3 (1979) 285-308; "Jesus of Nazareth in the Christology of 1Pe," en HJ 28 (1987) 292-304; "Jestis en in carta als Hebreus," Butleti de l'Associació Biblica de Catalurya, Suplement, 4 (1984) 84-97: "La vida de Jesús en el evangelio de Juan," Revista Latinoamericana de Teolog6, 3 (1986) 3-43.

23. Los textos que te cith scn suficientemente conocidos y no vamos a detenemos en hacer una liste de los mismos. Como ejemplo valgan los siguientes: "nacido de mujer..." (Gal 4, 4); "de la descendencin de David seguin la eame..." (Rom 1, 3); "obediente hasta la muerte y muerte de cruz" (Fil 2,7); "lı mansedumbre y la benignidad de Cristo" (2Cor 10,1); la cita de la tradición de la institución de la eucarisira (1Cor 11, 23-25); la debilided de Cristo, hecha patente sobre todo en la muerte $(2 \mathrm{Cor} 13,4$ cf. 11,30 y 12,5.9.10, etc); y los textos en donde Jesús es presentado como ejemplo y punto de referencia de la vide de Pablo: 2Cor 4, 7-15; Fil 2, 3-5; Rom 6 y 15,7. Se puede encontrar un resumen de detos en muchas introdueciones a Pablo: E. Eichholz, El evangelio, pp. 157-303; J. Blank, Paulus und Jesus, pp. 323-324; contrasta con ellos, en cambio, G. Bornkarmm, Pablo de Tarso, pp. 291-302.

24. Hay aqui un tama de un ciento grosor que conviene tener presente, aunque no podemos ampliarlo. Puede verse lo que escribl acerca del evangelio de Juan: "El cuarto evangelio y el tiempo," EE 57 (1982) 129-154, especinlmente pp. 152-154.

25. Estr afimación es central pare lo que decimos en este trabajo y, de hecho, constituye la aporiación má seria de la moderna crlica biblio a partir del conocido libro de M. Kahler sobre el Jesús historico y el Cristo de la fe. Dice en este aentido W. Trilling: "porque eate Jesús real, es decir, el Jesús verdadero e irequivoco, es el del kerigmo, el de la fe cristiana y el de la predicación cristinne" (subnyado del autor): Jesris y los problemas de su historicidad, Salamanca, 1975, p. 20.

26. El interts del Nuevo Tertamento por Jení nace de la relevancis de Jesús para la identidad de le experiencis cristienn la cual corre viempre el peligro de disolverse en une gnosis atemporal: "Jesú de Nazared, criterio de idenlidad cristians según el Nuevo Testernento," Todos Uno, Revista de pastonl vocacional, 82 (1985) 9-25.

27. Por lo que ubemos a ueves del Nuevo Tertumento, euto ue puede decir de la predicación cristiana primitiva en generil. Es un dato a la vez claro y corprendente que la predicación de los primeros cristianos no se centro en loa hecbos de la vide de Jesus. En eate sentido la aparición de lo que alguno liamen el genero literrio "evangelio" fue una innoveción altamente original. Cosa que no tenemos siempre ouficientemente en cuenth. Puede verse, entre ouras, la aportación ya clfísica de W. Marien, Dor Evangelist Markus. Studien zur Redabtionsgeschichic des Evangeliwns, FRLANT 67, Gütingen, 1956 (hay treducción castellme).

28. De una forma erpecinlmente subrayade por R Slenczka, Geschichlichkeit und Personsein Jesu Christi, Forrchzzynt. und okum. Teol. 18, Gäaingen, 1967. Pero esto ya puede hallarse en los arifallon de Kroemmn ( $f$. supra, noten 17 y 18), J.M. Robineon (cfr. noch 21). Una crítice especialmente penetrote en F. Hahn, "Methodologiache," Pp. 60-63.

29. Cfr. los trabajos citedos on la note 22 supra.

30. Lo que decimoa no es que astos textos no renn ousceptibles de uns argumenteción sobre ha realidad "zerren" de Jexú. Mí bien decimos que el punto de min desde el cusl deberfumos leer estos textos deberin ser mils paulino y menos inchrico. En otns palnbres, el molde en que estos textos funcionen ordinnriamente como indicadores de le realided erreme de Jesúa no es paulino y se eaca de otru obna del Nuevo Tertamento. Un argumento intereamie a la luz de ertos texlos puede encontrante en G. Eichholz, El evangelio de Pablo, pp. 157-303.

31. Probablemente esto deberis matizarse porque se trit de aporreciones casi siempre generales.

32. Aunque Pablo no descanoce la dintuncie que lo separe de los hechos de Jeaús, como lo muestran clanmente los corinos. Pero el problema no es ai los hechos 100 hechos del pasado. El problema es mils bien ai estos hechos han quedado de ul maners audos al paendo que no pueden ser preserier. Br evidente qoe, pare Pablo, el pasado se hace presente y configure le realided actual. En exe sentido ain enbargo "ni el pasedo ni el futuro... pueden separnmon del amor de Dios que re menifiante en Cristo Jexú," Rom 8, 38-39.

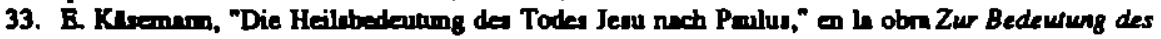
Tades Jerk Eugetische Beitrdge, Gilteraloh, 1967, pp. 11-34, sobre todo pp. 30-34. 
34. No queremos implicar que el resto del Nuevo Tesumento no muestre un interts roteriologico en la vida de Jesús. Lo que queremos subneyar es que el marco paulino donde se ha de inseribir su posible interes por la realidad humana de Jesús ha de ser forzosamente la coteriologia: "Die Menschheit Christi ist von ihm ganz und gar soceriologisch geschen und im Zusammenhang damit heilsgeschichulich," J. Blank, Paulus und Jesus, p. 324.

35. Cfr. X. Alegre, "El cos ressuscilat segons 1 Corintis 15. Apunt d'antropologie panline," publicado en Bullesr de I'Associacio Bblice de Calalunya, Suplement 2 (1982) 66-85.

36. Es este un terna un conocido y tratado que no es necesario subnyarlo. Pero, en cembio, canviene no olvidarlo ni pasarlo por alto en menera alguna.

37. "El acento, sin embargo, consiste en que la acción de Dios en comparación con la acción del hombre (aqul se piensa on una posibilidad extrema del hombre) carece de analogia. Asl le comparación permite conocer lo incomparable Aguf estr el scento. Si yo lo entiendo rectamente, Pablo ncentia precisamente el IGrite de la compancion," G. Eichholz, El evangelio de Pablo. p. 243. Subrayedo del autor.

38. Lo que resulta problernático es la prioridad cristologica. Pero par Pablo este el el punto fundamental de su argumentación. Recordemos los textos claves de Rom 5, 12-21 y 1 Cor 15. Podrímos decir que la prioridad cristologice es esencial par Pablo en la medida que es umbion una prioridad antropológica. Si no fuera asl, no tendria valor salvifico. Esto se recogert mis adelante, porque resulta muy importance (efr. sobre todo lh nota 68 infra).

39. Aspecto tratado y subrayado por $X$. Leon Dufour en su obre Jesús y Pablo ante la muerte, Madrid, 1982, especialmente en las Pp. 173-205 ("Pablo ante Jesús en la cruz").

40. "Und entsprechend meint Liebe bei Paulus stets die Bekundung des Daseins fîr andere, konkrea und besonders nachdricklich zumal in Sterben," E. Kisemann, "Die Heilsbedeunung," p. 17.

41. Este aspecto lo hemos de dar por supuesto, aunque resulu muy importante par lo que venimos diciendo. Cfr. U. Luz, Das Gesehicherverstedndnis des Paulus," München, 1968, Pp. 44-63 ("Hermeneutische Bewegungen und Geachichoverständnis") y el resumen de las pp. 83-84.

42. Lo cual en modo alguno niega que Dios es umbien el Seflor de ha hirtoria Pero, precisamente en cuanto Señor, no le estí sometido. Cfr. Rom 5, 12-21.

43. Rom. 4, 17; efr. 2 Cor $4,6$.

44. Este es un esquema hermeneutico que ha sido muy subrayado en nuestros ding. Uns presentación muy clan en G. Bomkamm, Pablo de Tarso (original de 1969). Se trats de un esquems hermeneutico extraodinariamente enraizado en la Biblis que, por tanto, we aplics umbien al resto del Nuevo Testamento.

45. De hecho la argumentación que hacemos ests baged por encima de lodo an la experiencis personal de Pablo. Es logico, por unto, que apelernos exchusivernente a las cartas euterticas del mismo Pablo: Rom, Gal, 1 y 2Cor, Fil, ITes y Flm. Pero, mis en concreto, ton los texion autobiograficos lo que nos interesn. En ellos, mas que una formuleción doctrinal, tenernos retnzos de la vida de Pablo que resulan únicas en el Nuevo Tesumento.

46. Se cile agul sobre todo $2 \mathrm{Cor} 4,6$, pero hny que tener especinlmente presenter otros textos camo por ejemplo Fil 3, 5-16 donde se da une valoracion mis bonda de lo que rignifice la novednd de la vida cristiann. Estumas ante la experiencis de Pablo como experiencis de Dion-creador (eff. supra nota 43). Le terńtica implicada enlaze con la formulación "vide de Jesús" que hernos de recoger más adelante.

47. "Aus eigener Kraft kanmt der Mensch aus der gezetslichen Daseinsform nicht heraus," J. Blank, Poulus und Jesus, p. 221.

48. Este punto se pasa por alto muchas veces: el argumento de Pablo en Gal 1-2 es, por encima de todo, que la buena noticia no es un anuncio humano, sino la fuerza de Dios ( cfr. Roon 1, 1617). En este sentido no solemente no viene de los de Jerusaltn (cosen suficientemente importente para Pablo en cualquier caso), pero ni tan sólo del cristianismo al que ha accedido Pablo (Antioqula, Damasco), lo cual no niega la imponancia de la tradición a la que Pablo se siente profundamente ligado.

49. La experiencia de la novedad radical como creación es lo que lleva a Pablo a hablar de la vida cristiana en temminos de libertad. Por la fe se accede a una nueva forma de ser que participa, de alguna forma, de la cualidad más profunda de Dios: el creador. Esto o lo que Pablo formula en 
términos de libernad (Cfr. Gal 5-6; Rom 6 y 2Cor 5, 11-21).

50. Todos estos textos hacen referencia a la experiencin que Pablo ha tenido de Jesuctisto y, de alguna manera, están relacionados con lo que llamamos la conversión de Pablo. Pero no pueden ser identificados sin mós, porque tienen matices muy diversos en ou contextos respectivos.

51. Un estudio altamente sugerente de este punto puede hallarse en K. Kenelge, "Apotenlyois Iesou Christou (Gal 1, 12)," publicado en el Festschrift R. Schnackenburg, Newes Testanent und Kirche, Freiburg-Basel-Wien, 1974, Pp. 266-281.

52. Esto es lo que dice directa y formalmente el texwo de Gal 1, 12, cegín al estudio cindo en la nota anterior, lo cual no se opone a una valonción poritiva de la tradicín por parte de Pablo.

53. "Das Wissen urn den irdischen Jesus erlangte also durch die gotuliche Apokelypuis ibber ihn sein Wert als die entscheidende Basis der missicnarischen Tätigkeit eeiner Boten," K. Kertelge, "Apokalypsis," p. 279.

54. Cfr. los concidos textos de Rom 1, 1; 1 Cor 1, 1; Gal 1, 1, etc. Su vocación como une misión en forma de doulos es un tema muy trabajado en la interpretación de Pablo. Puede verse el arículo de K. Kertel ge citado o también el libro de J. Blenk, Paulus wad Jesus, sobre todo en les pp. 222 230.

55. Se trata de un texto sorprendente en la literatura paulina: "porque, ai predico la buena nueva, no tengo ningún motivo de gloriame de ello, ya que se me ha impuesto como una obligacion; y lay de $\mathrm{ml}$ si no predico el evangeliol" (1Cor 9, 16). ¿Cómo liga esto con la liberrad paulina? Cfr. la nota siguiente.

56. Resulta especialmente penetrante en este sentido el trabajo de E. KKisenann, "Une venión paulina del 'amor fati"m publicado en Ensayos eregetticos, Sulemanca, 1978, pp. 51-71.

57. Eato es algo que pasemos por allo muchns veces. Lo que Jesín dijo o hizo no es norme en el sentido de ley, aino buena noticia en el rentido de alvación y libencín. Puede vene el unbajo citado en la not siguiente.

58. H. Schürnann, "Das Geserz des Christus (Gal 6, 2). Jesu Verhuluen und Won sl leszgillige situliche Norm nach Paulus," publicado an el Festschrif R. Schneckenburg, Newes Testament wnd Kirche, Freiburg, 1974, pp. 282-300.

59. "Die Liebe der Selbstaufgabe und Selbstemiedrigung Chriri int nech Paulus letze Narm und Kraftquelle sinlichen Verhaliens... Es ist die Tore des Herm die er edbat gelebe hat...," ibid., p. 300.

60. De hecho este terna se he relacionado muchas veces con el conocido texto de $2 \mathrm{Cor} 5,16$, al canal se han dedicado gran número de trabajos. Sin enbargo, hoy resulin bien patente que el kala sarka determina el sentido del verbo ginoskeein y no le realidad de Cristo. Por otro hado, hay que decir que en este fragmento paulino mis que ante un prognma teológico determinado (H. Conzelmmn) estamos ante la presentaeión de une nueva eupa de la salveción, innugunad con le muerte de Jesus, en la que Dios ha unnsformado la simación de la humanidad (y no e6lo de los creyentea): J.W. Fraser, "Paul's knowledge of Jesus: 2Cor 5, 16 ance more," publicado en NTS 17 (1971) 293.313.

61. En el fondo se implica en este modo de enfocar el problems une valonarón enormemente positivista de la historia: como si historia equivaliera a cantided de detos. Es bien patente que no podemos medir el valor o sentido de la realidad humana de Jenú para un auror a unvé de la cantidad de información que éste proporcione Unas reflexionea en este centido pueden hallarte en J. O. TuñI, "El cuarto evangelio y la cuestión historica," EE 50 (1975) 55-76, wobre codo PP. 63-66.

62. Este punto ha sido tratado en muchas ocasianes. Puede verse, cano ejemplo, el unbajo de H. W. Kuhn, "Der irdische Jesus bei Paulus als traditionsgeschichtliches und theologisches Problem," en ZThK 67 (1970) 295-320, que tome como punto de referencie el conocido estudio de D. Georgi sobre los adversarios de Pablo en 2Cor (Die Gegner des Paulus in 2.Korivtherbrif, Heidelbers. 1964). Tambien este enfoque metodologico esti a la buse del unbajo de Gingemanna cirado on la noth 7 supro.

63. Este es un punto fundarnental para lo que decimos en este tnbajo y, como resula patente, we trata de un esquema hermentutico utilizado pan interpreter los textos paulinos, tobre todo los 
autobiograficos. Le mediación de Pablo y de su vida resulta fundernenul pare no converir la labor de interprecación en un ejercicio meramente concepanal. Este a el peligro al que han nucumbido los trabajos citedos supra en la noth 20. Vése también ln nota siguiente.

64. Precisamente porque Pablo es la mediación necesaria parn conocer a Jesús. Pero entconces resulta que la vida de Jesús puede ser conocida a traves de la vida de Pablo. Y, en este sentido, de alguna forma la vida de Jesús es la vida de Pablo. Esto conatinrye un programa de interpretación de las carras de Pablo que debería tomarse en serio.

65. A pesar de que al concepto de imilación no es identico con el de seguimiento. Sin embargo, in imitación paulina no queda atrás ropecto del seguimiento evangelico. Hay equl un aspecto implicado que se deberfa analizar mis a fondo: de la manera como Pablo ha vivido el cristimismo (es decir, la vida de Jesús) se podria deducir que no sólo no nos consra que Pablo escribien evangelio alguno, sino que, dada su peculier experiencia de Jesis, no podia haberlo escrito.

66. Hemos de dejar de ledo el tema del Espirin que, siendo fundamentel par todo lo que decimos, nos Levarfa a un tema demasisdo importante, que supere los límites de este trabajo. Sin anbargo, hay que recordar por lo menos que si el eristimo puede tener la mente de Cristo y, en defíniliva, orar de la misma manera que Jesús onba (Abbd), ello se debe al Esplritu: cfr. Ram 5, 5; 8, 9: Gal 4, 6; ICor 2, 12, etc.

67. Tal vez esté aquf la razḱn más nonda de una cieru connaturalidad del mundo cocidenisl con Pablo $y$, en carnbio, de una clare sintonle del tercer mundo (mayormente América Latina) onn in presentación namativa de los evangelios (sobre todo sinópticon). Cfr. lo que decimos en la note 12. infra.

68. Es bien conocido que la interpresación bultumanniena de Pablo (sobre todo la que tenemos an mu Theologie des nemen Tesiamenss) puso un Enfasis nouble en la interpresción antropologica de los escritos paulinos. En cambio E. Kisemann ( $f f$ r. sobre wdo ou obn Pallinische Perspelativen, Tübingen, 1969) y otros (p.e. J. Fitzmyer, G. Eichholz) contraponen a este interpretecín antropológica una interpretación mís cristológica de los escritos paulinos. Tal vez lo que decimos contribuye a deshacer esta altemativa. Si hemos de interpretar el Jento paulino a trof́a de la vida y de la experiencia de Pablo, entonces resulta inevitable que la critologin tiene una vertiente antropologian. Por ouro lado ya hernos dicho antes que uns interpretación de Jerri en los grandes textor paulinos (Rom 5, 12-21; 1Cor 15; 2Cor 5, 11-21) es, al mifmo tientyo y necerariemente. uns interpretación antropológica. Este es el clrculo hermeneutico que debemos tener presente pare comprender a Pablo. El punto de entrada (y el punto de enlece con nuestra coodición humana) es en todo caso ha experiencin de Pablo. Este es un especto que pide une etención mayor de h que aqui podemos dedicarle.

69. Solo es posible meneionar la problemítica implicada en exe terna. En el fondo la conocida distinción entre sentido literal y sentido espiritual toma cuerpo on la escoele alejandrina de Clemente y Origenes (cfr. H. de Lubac, Histoire et Esprif. L"intelligence de IEcriture doprds Origene, Paris, 1949). Pero esta distinción eltamente fruculfere desde un punto de virn hermeneutico ( $f$ fr. H. de Lubac, Exégdse Medievale, 4 vols., Paris, 1959-1964, sobre todo el volumen II) fue a parar en una interpretación fatal pan la Biblia: la que presenta Santo Tamis (aunque no es original suya, efr. Exfgese Mtdityale, voL IV. pp. 272-285. 286-302) an le Summa Theologica (I, I, 10, ad 1: nulla confusio sequitw in Sacra Scriptura, cwo omres sensus fundentwo super unwm, seilicet lisferalem, ex quo solo potest trahi argumentwon ). (Solo el centido lietenl es válido para le Teologial Desde entances el sentido espiritual ha quededo al margen de la reflexión teológica. Pero, adernís, en nuestros dís la distinción ha sido decinive pare la publicacion de la Divino affante Spiritu (ffr. J. Levie, La Biblia, palabra humana y meneaje de Dias, Bilbeo, 1960), aunque, lodavis hoy, resulu sospechosa cunlquier interpreleción que vaye - parar al sentido espiritual. Todo esto deberla revisare mueho mir de lo que permite una breve nots aclaratoria. Lo que decimos en estas páginas muestse un camino de allida de un inpasse que, adernds, hace esteriles no pocos esfuerzos de la exégesio scturl, la canl quicien libnare de un callejón sin salide que la ahoge y la banaliza.

70. Quedan una serie de cuestiones pendientes que siguen preocupíndonos y que no podemos reeolver - In luz de la experiencia de Pablo. Vamos a mencionar solo dos: 1) (hine que purno la 
presentución cristológica de Pablo (y tumbien su experiencia ) tiene el peligro, no de un docetismo, que ea el peligro de las presentaciones evangelicas (mayormente de In), sino más bien de un adopcionismo? La exposiciones de Pablo, Lhan puesto las cautelas suficientes para deshacer este posible malentendido? Cfr. lo que decimos supra en la nota 10,2), ino podría ser que el vivir, morir y resueitar de Jesús sean una imaginación, una alucinación de Pablo? Ciertamente que esto es posible, pero no lo podemos aclerar a la luz del mismo Pablo. Esta pregunta no se la plantea Pablo. Esur convencido de que Jexú fue traicionado y murí en una noche en la cual acababa de instimir el memorial de su vida y de su muerte. $Y$ que resucito. Si Pablo se equivoca en esta apuesta queds pendiente de complementación (recordemos que hay muchos otros documentos en el Nuevo Tertemento) y de constalación. Por lo que el sabe la realidad no ofrece dudas al respecto. Pero es tore un problema que seguirt eaveiando al creyente de todos los tiempo. Sólo al funal serf posible consuntar ai ls interpreteción es correcta. He aqul el atractivo y la apuesta de la vida vivida como imineían de Jesús. La garmitle es el mismo Jesús presente en la fuerza del Espíritu. En elgún sentido estamos wodos muy cerea de Pablo. 